\title{
Last-male sperm precedence in Rhynchophorus ferrugineus (Olivier): observations in laboratory mating experiments with irradiated males
}

\author{
S. Musmeci ${ }^{1}$, S. Belvedere ${ }^{2}$, R. Sasso ${ }^{1}$, S. Arnone ${ }^{1}$, \\ M. Cristofaro ${ }^{1}$, P. Nobili ${ }^{1}$, A. La Marca ${ }^{3}$ and A. De Biase ${ }^{2 *}$ \\ ${ }^{1}$ ENEA, Italian National Agency for New Technologies, Energy and \\ Sustainable Economic Development, Via Anguillarese 301, 00123 S. Maria di \\ Galeria (Rome), Italy: ${ }^{2}$ Department of Biology and Biotechnology 'Charles \\ Darwin', Sapienza Rome University, Viale dell'Università 32, 00185 Rome, \\ Italy: ${ }^{3}$ BBCA-onlus, Via Angelo Signorelli 105, 00123 Rome, Italy
}

\begin{abstract}
The Red Palm Weevil (RPW) Rhynchophorus ferrugineus (Olivier 1790) is an invasive pest from southeastern Asia and Melanesia that in the last 30 years has spread widely in the Middle East and Mediterranean Basin. Its stem-boring larvae cause great damage to several palm species of the Arecaceae family, many of which are economically important for agricultural and ornamental purposes. Therefore, great attention has recently been focused in studying this species to identify sustainable and effective eradication strategies, such as sterile insect technique (SIT). The rapid spread of RPW is associated with its high reproductive success. To evaluate the suitability of a SIT strategy, particular physiological and behavioral aspects of RPW reproduction, such as the presence of polyandry and post-copulatory sperm selection mechanisms, were investigated. To determine paternity of progeny from multiply mated females, double-crossing experiments were carried out confining individual females with either a wild-type male or a $\gamma$-irradiated male (Co-60). Fecundity and fertility of females were scored to evaluate post-copulatory sperm selection. Results showed that progeny were almost exclusively produced by the sperm of the second male, suggesting that a last-male sperm precedence is expressed at high levels in this species, and providing interesting insights for an area-wide RPW management strategy such as the SIT.
\end{abstract}

Keywords: last-male sperm precedence, paternity assignment, sterile insect technique, Red Palm Weevil

(Accepted 8 May 2017; First published online 3 October 2017)

\section{Introduction}

The Red Palm Weevil, Rhynchophorus ferrugineus (Olivier, 1790) (Coleoptera, Dryophthoridae; hereafter RPW), is a polyphagous invasive insect pest, feeding on more than 20 species of palms in the family Arecaceae (Murphy \& Briscoe, 1999).

*Author for correspondence

Tel.: +39-06.4991.4744

Fax: +39-06.4958.259

E-mail: alessio.debiase@uniroma1.it
The weevil's primary distribution is Southeastern Asia and Melanesia but, beginning in the 1980s, RPW spread to the Middle East, and since the early 1990s reached the Mediterranean Basin through the trade of infested palm trees (Faghih, 1996; Kehat, 1999; Rugman-Jones et al., 2013).

Spread of RPW is causing great economic damage; RPW is now on the A2 EPPO list (European and Mediterranean Plant Protection Organization) for quarantine pests (EPPO, 2015) and is considered the main pest of the date palm in arid regions of the Middle East and North Africa where it is widely cultivated as an important food resource. Larval instars burrow into the stem and/or the basal leaf shoots of the host 
plant and their tunnels can reach the main meristem, causing leaves to fall and often the death of the palm tree (Faleiro, 2006; El-Mergawy \& Al-Ajlan, 2011). One of the key features of RPW'S widespread and harmful invasion is its high reproductive success, which has been broadly investigated in previous studies (Esteban-Durán et al., 1998; Kaakeh, 2005; Prabhu \& Patil, 2010; Ju et al., 2011). Females can oviposit several hundred eggs during a long oviposition period lasting several weeks (Ince et al., 2011). RPW females can also lay fertile eggs until 1 month after copulating (Kaakeh, 2005), suggesting their ability to store and maintain large amounts of viable sperm in the spermatheca. In addition, depending on local climatic conditions, the species can complete multiple generations per year, even within the same tree (Faleiro, 2006; Dembilio \& Jacas, 2011). High percentages of RPW fertilized females were recorded in field traps baited with aggregation pheromone several kilometers from their colony, suggesting high potential for genetic exchanges between distant colonies (Cristofaro et al., 2011; Musmeci et al., 2013).

These behavioral and biological characteristics make RPW difficult to manage by conventional methods, such as the use of insecticides. More suitable approaches based on area-wide strategies, such as the sterile insect technique (SIT), could improve the likelihood of successful RPW control, especially considering physically and ecologically isolated or sensitive areas (Klassen, 2005), alone or in combination with other biological control strategies (Llácer et al., 2013). The SIT can be defined as a pest control method based on the use of inundative releases of sterile male insects of the same pest species whose ability to mate has not been affected, in order to introduce a genetic load that would lead to its suppression or even eradication (Knipling, 1955, 1968; FAO, 2005).

Exposure to ionizing radiation is widely used to sterilize insects (Robinson \& Hendrichs, 2005) and SIT has been successfully applied for several pest species, as a basic component of area-wide integrated pest management (Klassen, 2005). It is essential for the SIT success that sterile males can compete against wild males, both in mating with wild females and fertilizing their eggs, making them unviable. In this regard, the application of SIT requires laboratory bioassays on the physiological and behavioral responses of the insect to sterilization. Many aspects of reproductive biology have to be fully described and in-depth studies on mating behavior and physiology are needed to inform management actions, in particular detailed knowledge of population dynamics and adult dispersal (Hendrichs et al., 2002; Klassen, 2005), in order to maximize the impact of sterilized insects on field populations.

Despite promising results of laboratory bioassays on the evaluation of SIT for RPW control, using chemo-sterilization (Rahalkar et al., 1975), X-rays, and $\gamma$-ray treatments (Rahalkar et al., 1973; Ramachandran, 1991; Lance \& McInnis, 2005; Gothi et al., 2007; Al-Ayedh \& Rasool, 2010; Prabhu et al., 2010) and preliminary field experiments (Rahalkar et al., 1977; Krishnakumar \& Maheshwari, 2007), the use of SIT for this species could be considered inappropriate due to the observation of multiple mating by females and the gregarious and cryptic behavior of the weevil (Whitten \& Mahon, 2005). According to Lance \& McInnis (2005) the success of mating between sterile males and wild females can be lost if the females remate with wild males, and preferentially use sperm from the latter for fertilization. However, polyandry does not necessarily negate the basic principles of the technique (Barclay, 2005; Whitten \& Mahon, 2005). In fact, if females of a species mate more frequently, the sperm from irradiated (sterile) males must be produced essentially at the same rate in order to effectively compete with sperm of wild males. Thus, the issue concerns not the level of polyandry but the competitiveness of sterile males that will be influenced by post-mating factors, i.e. the ability to induce mating refractoriness in females, sperm competition and/or sperm precedence, depending on the species (Simmons, 2001; Harari et al., 2003; Lance \& McInnis, 2005).

As regards to the reproductive behavior of RPW, Inghilesi et al. $(2014,2015)$ highlighted a complex and promiscuous sexual behavior, with males looking for new mating partners immediately after copulation, and multiple mating both under laboratory and natural conditions. These behavioral data, together with the possibility that females could store and utilize different mates' sperm, are the critical factors that could influence the success of eradication programs (Barclay, 2005). The occurrence of promiscuity in a species, however, does not necessarily translate into multiple paternity among the offspring of the female, because of the existence of post-copulatory sexual selection mechanisms (Danielsson, 1998). Studies of the effects of mating order on fertilization success, typically known as the proportional paternity of the second male ( $P 2$-value; Boorman \& Parker, 1976), have shed light on the relative influence of post-copulatory male-male competition and female choice on sexual selection (Squires et al., 2015).

Paternity assignment can be inferred by the sterile male technique (Boorman \& Parker, 1976). Accordingly to the complete scheme of paternity assignment, virgin females can be doubly mated with pair of virgin males in the following order: sterile-sterile, normal-normal, normal-sterile, or sterile-normal. In fact, the level of unfertilized eggs has to be compared to the percentage of egg hatching recorded on the double mating with normal male in order to obtain a correct estimation of the sperm precedence (Cook et al., 1997). On the other hand, sperm of irradiated males could be less viable than those originated from normal males (Barclay, 2005), giving rise to $P 2$-values which could partially depend on the order of mating (normal-sterile or sterile-normal). The magnitude of last male priority varies considerably among insect species depending on various ecological factors, with $P 2$-values ranging from 0.02 to 1.00 (Gwynne, 1984). This information is crucial to determine the potential parameters of a SIT strategy, as such as the sterile male:wild male ratio (Lee et al., 2003; Lance \& McInnis, 2005).

The goal of this study was to investigate post-copulatory sperm selection mechanisms in RPW through laboratory experiments involving remating with normal and irradiated males. This approach allowed us to make a first assessment of the $P_{2}$-values occurring in this species.

\section{Materials and methods}

\section{Insects and male irradiation}

In order to obtain virgin and physiologically uniform individuals to be used in tests of remating for paternity assignment (Boorman \& Parker, 1976), a laboratory colony of RPW was established from insects trapped with Intrachem Rhyncho Trap® (activated with Rhypher 220) or collected from downed palms in central Italy (Rome Province). Rearing was carried out in a growth chamber $\left(29^{\circ} \mathrm{C} \pm 1 ; \mathrm{RH}=90 \% ; \mathrm{L}: \mathrm{D}=12: 12\right)$ on a diet consisting of slices of apple (cv Golden Delicious) mixed with coconut fiber. On this pabulum, biological parameters (e.g. lifespan, larval weight, adult behavior, and 
reproductive performance) were similar to those observed on insects collected from the field (Arnone et al., 2014). Thus, insects reared entirely in the laboratory could be used to monitor the whole reproductive phases of RPW, from the adult eclosion up to the end of the oviposition period.

Adult males were irradiated with a Cobalt-60 source of $\gamma$-rays at the ENEA facility 'Calliope' (Baccaro et al., 2005) at a rate of $12.5 \mathrm{~Gy} \mathrm{~min}^{-1}$. The irradiation dose was $80 \mathrm{~Gy}$, because males treated at this dose, in spite of a reduction of their adult lifespan (about 20 days in comparison to the 100200 days recorded for untreated males), mated as frequently as non-irradiated males and $100 \%$ of eggs laid were inviable (Cristofaro et al., 2011; Musmeci et al., 2013).

\section{Experiments}

Three types of treatments were carried out: the A and B bioassays were set up using newly emerged individuals reared in laboratory, while a third bioassay (A Wild, hereafter AW) was performed using wild individuals collected from traps. A double mating scheme was performed.

For the A and B bioassays, a virgin female was singularly confined with one male in each of two subsequent experimental phases: in the A scheme, the first male was untreated, followed by the second experimental phase in which the first male was replaced with an irradiated one (normal-sterile mating order). Treatment B was carried out following the same experimental design but in the reverse order (sterile-normal mating order). Nine repetitions were made for both treatments. A normal-normal mating order was used as control, to verify reproductive parameters (nine repetitions). Since in previous experiments mating with sterilized males produced $100 \%$ inviable eggs, the sequence of mating sterile-sterile was considered unnecessary.

The following experimental procedures were performed to record reproductive parameters. Adult pairs were singularly confined in transparent plastic boxes $(12 \times 8 \times 10 \mathrm{~cm})$ provided with half an apple that served as substrate for feeding and oviposition. Since pre-copulatory interactions do not necessarily lead to successful intromission (Mazza et al., 2014), mating was assessed by visual observation based on the recording of aedeagus in the female genital opening for at least one minute. Every 3 days the half apple was replaced with a new one in order to provide a fresh substrate. At the ninth day, males were replaced in each box. Since females who copulate several times lay more fertile eggs than females which copulate once (Llácer et al., 2013; Mazza et al., 2016), females were kept with males throughout the experiment. Fecundity and fertility were reported at $6,9,12$, and 15 days, thus the I and II records were made during the mating with the first male, the III and IV after the male was replaced. Fecundity was recorded collecting all eggs laid on the apple and all the eggs were kept isolated in a multiwell plate ( 24 wells, $1 \mathrm{~cm}$ diameter, one egg/well) covered with moistened filter paper. Multiwell plates were kept in a growth chamber at $29^{\circ} \mathrm{C}$ and with a $\mathrm{RH}$ close to $100 \%$ to avoid egg dehydration, and stored for at least 6 days, in order to allow all viable eggs to hatch. Fecundity was expressed as oviposition rate (number of eggs laid day ${ }^{-1}$ ). Fertility was checked daily and expressed as number of hatched eggs day ${ }^{-1}$ and percentage of eggs hatching. The eggs were considered unviable if they did not produce larvae after 6 days (Abdel-Azim et al., 2012).

A third treatment (treatment $\mathrm{AW}$ ), equivalent to treatment A, was carried out with the aim of assessing second male sperm precedence using wild individuals. The rationale was to assess if the sperm selection mechanisms, in insects collected from field, could be influenced by the different environmental conditions existing in nature (host plant, climate factors, etc.) in comparison to the laboratory. For this purpose, adults were captured in pheromone traps located in four different sites of Rome Province (Musmeci et al., 2013). A consistent number of females were randomly sampled in laboratory and individually confined in plastic cages. Then they were observed for fecundity and fertility, as previously described for experiments $\mathrm{A}$ and $\mathrm{B}$, at 6 and 9 days (I and II records), in order to ascertain that mating in the field with wild males had already occurred. Afterwards, 10 females showing viable eggs were randomly chosen, and each one was coupled with a sterilized wild male, and at 12 and 15 days (III and IV records) fecundity and fertility were checked. Females were allowed to stay with males until the 18th day. Successively, with the purpose to detect any recovery of egg fertility after mating, the sterile male was removed and females were kept isolated for another 9 days during which the same observations on reproductive parameters were repeated every 3 days (ten repetitions). As a control, gravid females captured in field were observed for reproductive parameters with the same procedure previously described, and then mated with non-irradiated wild males (six repetitions). All experiments were carried out under the same laboratory conditions as in colony rearing (described above).

\section{Data analysis}

Statistical analyses were performed using PASW Statistics 17, Release Version 17.0.2 (SPSS Inc., 2008). The mean rate of oviposition per female (no. eggs day ${ }^{-1}$ ), the mean rate of eggs hatched (no. eggs hatched day ${ }^{-1}$ ) and the mean percentage of eggs hatched per female [calculated as (eggs hatched $\times$ laid eggs $\left.^{-1}\right) \times 100$ ] were analyzed. Since the variance was not homogeneous among groups and non-normal within groups (as verified by Levene's test and Shapiro-Wilk's test, respectively), non-parametric tests were used.

The Friedman's test for related samples was performed within each treatment in order to test significant changes in female reproductive parameters during four observations of the bioassays: I and II (at 6 and 9 days from the beginning of the treatment with the first male, or isolated in the case of treatment AW), and III and IV (at 12 and 15 days, after remating). This is the reproductive phase in which the rate of fertility is virtually constant, reaching the highest values in laboratory conditions (eggs hatching of $86 \% \pm 2.9 \mathrm{SE}$ ). By contrast, as previously observed by Musmeci et al. (2013), 0\% of eggs sired by irradiated males ( $80 \mathrm{~Gy}$ ) hatched during the reproductive life span of a female. Thus, any statistically significant deviation from these values could be reasonably attributed to the effect of remating.

The measurement of the proportion of eggs fertilized by the sperm of the second male $\left(P_{2}\right)$ was calculated for the treatment AW according to the formula proposed by Sillen-Tullberg (1981) and modified by Cook et al. (1997). In fact, in this case the experiment lasted for 27 days, allowing us to obtain $P_{2}$-values covering most of the oviposition period as well as to verify any recovery of eggs fertility after male removal (the period from 18 to 27 days after the start of the experiment). We reported the proportion of unfertilized eggs scores coming from second mating with sterilized males as $1-$ $P_{2}$, hereafter shown as $P_{2 S}$ (Cook et al., 1997). 
Table 1. Remating experiment with irradiated males for the A (normal-sterile male order), B (sterile-normal male order) and AW (equivalent to A treatment but starting with naturally mated females from the field) treatments.

\begin{tabular}{|c|c|c|c|c|c|c|c|c|}
\hline \multirow[t]{2}{*}{ Treatments } & \multirow{2}{*}{$\begin{array}{l}\text { Type of mating } \\
\text { Order } \times 0^{\star}\end{array}$} & \multirow{2}{*}{$\begin{array}{c}\text { Records } \\
\#\end{array}$} & \multicolumn{2}{|c|}{ Rate of eggs laid } & \multicolumn{4}{|c|}{ Rate of eggs hatched } \\
\hline & & & $\#$ day $^{-1}$ & SD & $\#$ day $^{-1}$ & SD & $\%$ & SD \\
\hline \multirow[t]{4}{*}{ A } & \multirow[t]{2}{*}{1 st $\times$ normal } & I & 4.78 & 4.13 & $4.42 \mathrm{a}$ & 3.93 & $90.3 \mathrm{a}$ & 9.0 \\
\hline & & II & 5.94 & 5.34 & $5.44 \mathrm{a}$ & 5.14 & $88.1 \mathrm{a}$ & 7.2 \\
\hline & \multirow[t]{2}{*}{2 nd $\times$ irradiated } & III & 6.07 & 4.45 & $0.15 \mathrm{~b}$ & 0.33 & $2.2 \mathrm{~b}$ & 4.2 \\
\hline & & IV & 4.91 & 2.17 & $0.00 \mathrm{~b}$ & 0.00 & $0.0 \mathrm{~b}$ & 0.0 \\
\hline \multirow[t]{4}{*}{ B } & \multirow[t]{2}{*}{ 1st $\times$ irradiated } & I & 5.25 & 3.44 & $0.00 \mathrm{~b}$ & 0.00 & $0.0 \mathrm{~b}$ & 0.0 \\
\hline & & II & 7.37 & 4.03 & $0.00 \mathrm{~b}$ & 0.00 & $0.0 \mathrm{~b}$ & 0.0 \\
\hline & \multirow[t]{2}{*}{2 nd $\times$ normal } & III & 6.67 & 4.29 & $4.60 \mathrm{a}$ & 4.35 & $61.8 \mathrm{a}$ & 33.0 \\
\hline & & IV & 6.15 & 3.30 & $4.65 \mathrm{a}$ & 3.32 & $72.6 \mathrm{a}$ & 25.0 \\
\hline \multirow[t]{4}{*}{$\mathrm{C}_{(\mathrm{A}, \mathrm{B})}$} & \multirow[t]{2}{*}{1 st $\times$ normal } & I & 4.86 & 5.07 & 3.90 & 4.39 & 79.8 & 16.7 \\
\hline & & II & 4.40 & 2.37 & 3.38 & 2.62 & 77.8 & 17.8 \\
\hline & \multirow[t]{2}{*}{2 nd $\times$ normal } & III & 8.90 & 6.23 & 8.38 & 5.90 & 93.0 & 10.3 \\
\hline & & IV & 5.05 & 2.34 & 4.45 & 1.82 & 89.8 & 11.0 \\
\hline \multirow[t]{4}{*}{ AW } & \multirow[t]{2}{*}{ - Isolated female } & I & $6.10 \mathrm{ab}$ & 1.66 & $5.37 \mathrm{a}$ & 1.88 & $87.7 \mathrm{a}$ & 17.0 \\
\hline & & II & $2.65 \mathrm{~b}$ & 3.29 & $2.50 \mathrm{a}$ & 3.21 & $91.7 \mathrm{a}$ & 17.3 \\
\hline & \multirow[t]{2}{*}{$-\times$ Irradiated } & III & $10.25 \mathrm{a}$ & 5.94 & $0.23 \mathrm{~b}$ & 0.34 & $2.6 \mathrm{~b}$ & 3.5 \\
\hline & & IV & $8.90 \mathrm{ab}$ & 4.69 & $0.03 \mathrm{~b}$ & 0.11 & $0.7 \mathrm{~b}$ & 2.3 \\
\hline \multirow{4}{*}{$\mathrm{C}_{(\mathrm{AW})}$} & \multirow[t]{2}{*}{ - Isolated female } & I & 5.50 & 2.68 & 5.28 & 2.82 & 93.1 & 7.4 \\
\hline & & II & 6.50 & 4.72 & 6.25 & 4.71 & 95.3 & 6.5 \\
\hline & \multirow[t]{2}{*}{$-\times$ Normal } & III & 14.08 & 7.03 & 12.58 & 6.37 & 90.3 & 7.5 \\
\hline & & IV & 6.17 & 4.39 & 5.50 & 4.30 & 83.3 & 18.2 \\
\hline
\end{tabular}

Values of the control samples $\left[\mathrm{C}(\mathrm{A}, \mathrm{B})\right.$ and $\left.\mathrm{C}_{(\mathrm{AW})}\right]$ are compared with the respective bioassays. Comparisons are made among the four observations of the bioassay: the first two records (I-II) before male substitution and the next two observations after male substitution (III-IV). Mean values with different letters statistically differ between them for $P \leq 0.05$ according to the post hoc Friedman's test.

Table 2. $U$ and $P$ statistics obtained from the Mann-Whitney test; comparisons were made among the same experimental records of each treatment and the control.

\begin{tabular}{|c|c|c|c|c|c|c|c|c|}
\hline \multirow[t]{2}{*}{ Treatments } & \multirow{2}{*}{$\begin{array}{c}\text { Type of mating } \\
\text { Order } \times{ }^{\star}\end{array}$} & \multirow{2}{*}{$\begin{array}{l}\text { Records } \\
\quad \#\end{array}$} & \multicolumn{2}{|c|}{ Rate of eggs laid (\# day ${ }^{-1}$ ) } & \multicolumn{4}{|c|}{ Rate of eggs hatched (\# day ${ }^{-1} \%$ ) } \\
\hline & & & $U$ & $P$ & $U$ & $P$ & $U$ & $P$ \\
\hline \multirow[t]{3}{*}{ A } & 1 st $\times$ normal & I & 30.0 & 0.953 & 28.5 & 0.900 & 11.5 & 0.229 \\
\hline & \multirow[t]{2}{*}{ 2nd $\times$ irradiated } & III & 20.0 & 0.667 & 1.0 & 0.003 & 0.0 & 0.002 \\
\hline & & IV & 31.5 & 1.000 & 0.0 & 0.002 & 0.0 & 0.002 \\
\hline \multirow[t]{2}{*}{ B } & 1st $\times$ irradiated & I & 20.0 & 0.707 & 4.0 & 0.004 & 0.0 & 0.002 \\
\hline & 2 nd $\times$ normal & IV & 21.0 & 0.716 & 27.0 & 0.957 & 15.5 & 0.217 \\
\hline \multirow[t]{4}{*}{ AW } & \multirow[t]{2}{*}{ - Isolated female } & I & 26.0 & 0.884 & 29.5 & 0.957 & 24.0 & 0.559 \\
\hline & & II & 15.5 & 0.667 & 15.0 & 0.175 & 23.5 & 0.943 \\
\hline & \multirow[t]{2}{*}{$-\times$ Irradiated } & III & 20.0 & 0.667 & 0.0 & 0.003 & 0.0 & 0.002 \\
\hline & & IV & 19.0 & 0.667 & 0.0 & 0.002 & 0.0 & 0.002 \\
\hline
\end{tabular}

Values significantly different from the control $(P \leq 0.05)$ are reported in bold type. $P$-values were corrected by the Benjamini-Hochberg method for multiple hypothesis testing.

The Mann-Whitney test for two independent samples was also performed for treatments $\mathrm{A}, \mathrm{B}$ and $\mathrm{AW}$ to record any significant difference among the same experimental records in female reproductive parameters, in comparison to the control sample. Due to the high number of comparisons (12), a Benjamini-Hochberg's correction (1995) for multiple testing was adopted. This method controls the false discovery rate and is recommended when two treatments are compared in multiple, related subgroups.

\section{Results}

The results of remating experiments with irradiated males for treatments A, B and AW are reported in tables 1 and 2 and figs 1 and 2. Regarding female fecundity (in terms of oviposition rate), no significant effects of the irradiated males were detected in treatments $\mathrm{A}$ and $\mathrm{B}$ during the different phases of the experiment, nor comparing the same periods with the control sample $\mathrm{C}_{(\mathrm{A}, \mathrm{B})}$ (table 1 and 2, fig. 1). Overall, values ranged from 4.40 to 7.37 eggs day ${ }^{-1}$ before male change and from

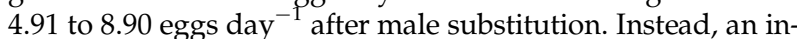
crease in oviposition rate was detected in the AW treatment, after the introduction of male. This increment was more consistent and statistically significant after remating with the irradiated wild male (table 1, fig. $2 \mathrm{AW}$ ), with the oviposition rate growing from 2.65 to 10.25 eggs laid day ${ }^{-1}$.

As to female fertility, statistically significant differences were recorded in the rate and percentage of eggs hatching 

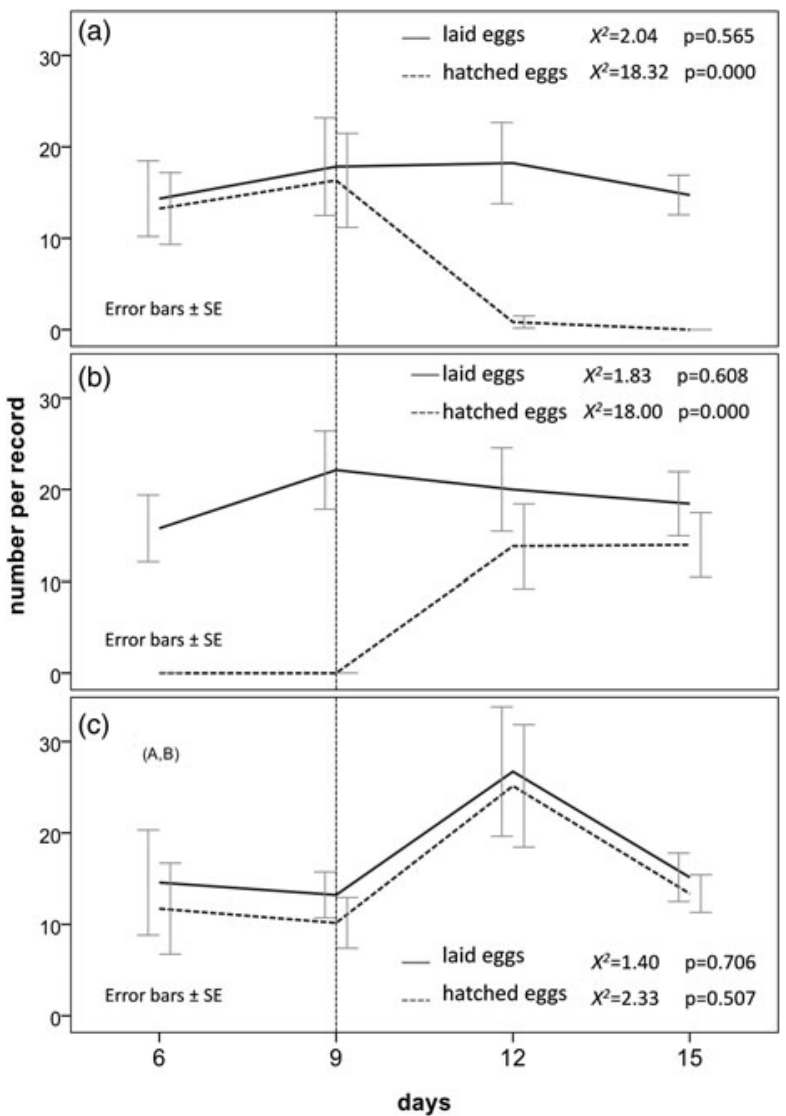

Fig. 1. Results of A and B treatments performed on individuals reared in laboratory. Virgin females are initially mated with a normal male (picture A) or an irradiated male (picture B). On the ninth day of the experiment, the male is replaced with an irradiated male (treatment A) or with a normal male (treatment B) and left free to mate. The control (male substitution with another normal male) is reported in c. The vertical dashed lines indicate male replacement. Friedman's test statistics $\left(\chi^{2}\right.$ and $P$-value) are reported near each reproductive parameter in the legend.

after remating in all treatments. After the substitution of a normal male with a sterilized male (treatment A), the hatching rate decreased from 5.44 hatched eggs day ${ }^{-1}$ to only 0.15 hatched eggs day ${ }^{-1}$ after male replacement and to zero in the next observation (table 1, fig. 1A). The differences among the different phases of the experiment were significant $\left(\chi^{2}=18.32, P<0.001\right.$, Friedman's test $)$ as well as among the corresponding experimental phases of the treatment and the control, according to the Mann-Whitney test (table 2, treatment $\mathrm{A}$, records III and IV). The opposite was observed in treatment $B$, where a hatching rate of 4.60 and 4.65 eggs $\mathrm{day}^{-1}$ (table 1) was observed in the two records after remating with no appreciable differences with the control (table 2, treatment B, records III and IV). No viable eggs were recorded in the first mating with the irradiated male (table 1, fig. 1B). On the contrary, eggs hatching recorded on the control were always high and, in spite of an apparent increment after male substitution [table 1 , fig. $1 \mathrm{C}_{(\mathrm{AB})}$ ], no significant differences were recorded among the different observations of the treatment according to the Friedman's test $\left(\chi^{2}=2.33, P=0.507\right)$. More in detail, a trend toward lower percentages of eggs hatching was recorded in comparison with the control (table 2, treatment B, record III) immediately after irradiated male was substituted with the normal male (values of $61.8 \%$ compared with the $93.0 \%$ of eggs hatching recorded on the control, see also table 1), even if these differences did not reached the threshold of significance.

Results very similar to treatment A were achieved in the case of treatment $\mathrm{AW}$, where the hatching rate decreased from 2.50 to 0.23 hatched eggs day ${ }^{-1}$ recorded after the replacement with the sterile male and finally to 0.03 hatched eggs day ${ }^{-1}$ in the next observation (table 1, fig. $2 \mathrm{AW}$ ). In this case also, a sharp drop of egg fertility was observed immediately after mating with the irradiated male and no recovery of viable eggs was observed until the $9^{\text {th }}$ day after male removal, when the experiment was stopped (fig. $2 \mathrm{AW}$ ). In fact, in spite of an increase in the oviposition observed after remating in the laboratory (table 1), almost $0 \%$ of eggs were viable after mating with sterilized males against a mean of $74.2 \% \pm 31.1$ of eggs hatching recorded on the control females after remating with normal males (table 1). As already observed for the A and $B$ treatments, the difference in rate of eggs hatching after the introduction of irradiated male was statistically significant, for both the reproductive parameters (fig. $2 \mathrm{AW}$ ) as well as the differences with the control (table 2, treatment AW, records III and IV). The control sample showed a gradual decrease in the eggs hatching rate after male removal, probably due to the aging of wild females [table 1, fig. $2 \mathrm{C}_{(\mathrm{AW})}$ ].

The last-male sperm priority score $\left(P_{2 \mathrm{~S}}\right)$ obtained from second mating of the experiment $\mathrm{AW}$ was $0.994 \pm 0.01$.

\section{Discussion}

Even if multiple mating appears common in the sexual behavior of this species, results obtained with the remating experiment (A, B and AW treatments) indicate a clear presence of last mating male sperm precedence. In particular, the proportion of progeny sired by the last male was close to 1.0 after remating experiment AW. All the bioassays on reproductive parameters indicated that paternity changed in $<3$ days after mating, almost completely excluding sperm from prior males.

The exclusive use of the last male's sperm was even inferred by changing the mating order of male types (irradiated, then normal and vice versa), both using laboratory reared females (treatments A and B) or fertilized females collected in field traps and then mating them with wild sterilized males (treatment AW). Furthermore, the effect of last-male precedence was recorded for the duration of the bioassay, since no recovery of fertility was detected up to 27 days in the AW treatment, even after removal of the irradiated male during the last 9 days. This result was also confirmed with observations till the end of oviposition period (up to 32 days after male removal) on a subsample of five replicates coming from the A and $\mathrm{B}$ treatments (data not shown).

In preliminary genetic paternity analyses - based on microsatellite genotyping (Belvedere et al., 2014) - where a virgin female was confined with a single male until the first copulation was completed, the first male was removed and replaced immediately with a second one. Results indicated that eggs were fertilized with the sperm of only the most recently mated male (Belvedere et al., unpublished data). These data highlight that the sperm selection mechanism in RPW is not dependent from a short viability of previous sperm contributions, confirming the results obtained in the remating experiments. 


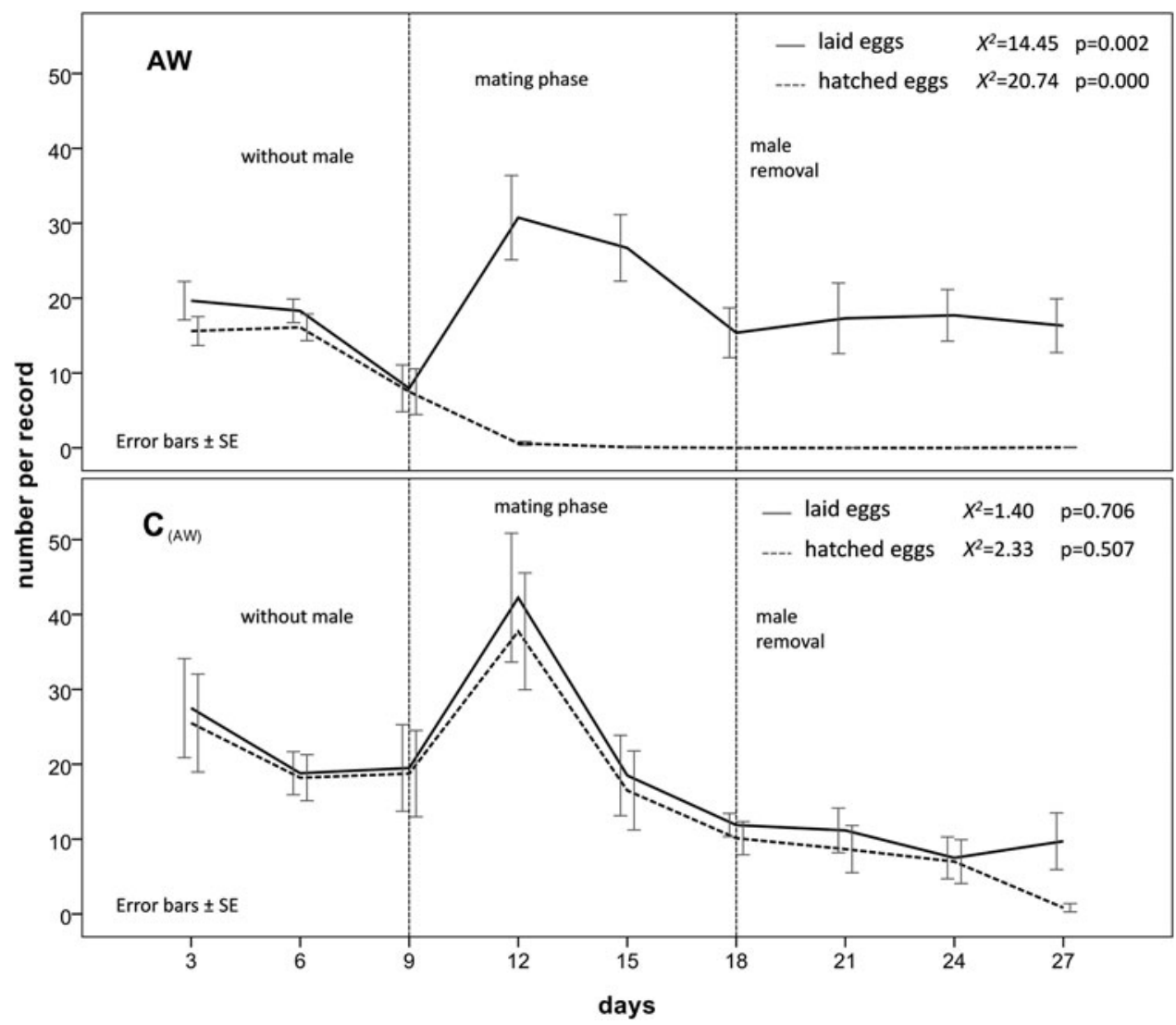

Fig. 2. Treatment AW carried out in the laboratory with individuals collected from field. The picture 'AW' above shows the test treatment: wild females are kept isolated for 9 days to assess their fertility and then are individually mated in the laboratory with wild irradiated males ( 9 days) and finally kept free to oviposit without the male for another 9 days. The picture ' $C_{(A W)}$ ' below shows the control treatment: in this case, after fertility assessment, the female is mated with a wild normal male. The vertical dashed lines indicate the male introduction and its successive removal at 9 and 18 days, respectively. Friedman's test statistics ( $\chi^{2}$ and $P$-value) are reported near each reproductive parameter and are referred only at the two recordings before and after the introduction of the male in the box.

Wide intraspecific variation in $P_{2}$-values is common in insects (Lewis \& Austad, 1990). High variability in $P_{2}$-values were observed within a population of the beetle Bolitotherus cornutus (Conner, 1995), while a $P_{2}$ of 0.25 was recorded using irradiated males of the coleopteran Callosobruchus chinensis thus showing a moderate level of first-male sperm precedence (Harano et al., 2008).

The $P_{2}$-value close to 1.0 found in this study, without appreciable differences among individuals, raises several interesting issues regarding RPW reproductive biology as well as possible future applications of SIT for this polyandric species.

A critical factor that makes sterile insect releases effective is the relation between $P_{2}$-values recorded in laboratory and levels of fertility observed in field (Scolari et al., 2014). In the case of RPW, the high $P_{2}$-values should allow for rapid suppression of the reproductive potential of the species, in spite of the high percentages of fecundated females existing in field.

In experiments simulating a natural-like social context (Mazza et al., 2016), irradiated RPW males did not differ in competitiveness from normal males with a consistent decline in female fertility recorded in the mixed normal-irradiated group. In addition, observations performed by electron microscope on the ultrastructure of irradiated RPW sperm did not reveal any important dysfunction or differences in comparison with non-irradiated sperm (Paoli et al., 2014). These recent literature records and our findings would make it possible to reconsider the SIT strategy as a potential component of an area-wide integrated pest-management program especially in wellisolated and restricted areas (i.e. oasis or islands). Nevertheless, further studies on the RPW mating system considering multiple variables (i.e. timing, number, duration and frequency of copulations; longevity and fitness of the sperm; presence of post-copulatory mate-guarding behavior) as well as observation on populations from different areas of the world are needed to understand better the mechanism underlying last male precedence (Simmons, 2001; Harari et al., 2003).

\section{Acknowledgements}

Authors are grateful to all colleagues and friends that helped our effort in some way; many by collecting samples to be analyzed and many in other ways. They are: M. Alfò (Sapienza University of Rome, Rome, Italy), S. Baccaro (ENEA FSN, Rome, Italy), R. Balducchi (ENEA SSPT-BIOAG, C.R. Trisaia, Italy), R. Cervo (University of Florence, Florence, Italy), S. Catarci (BBCA Onlus, Rome, Italy), E. Colonnelli (Rome, Italy), F. Di Cristina (BBCA Onlus, Rome, Italy), G. Jona Lasinio (Sapienza University of 
Rome, Rome, Italy), G. Mazza (CRA, Florence, Italy), A. Paolini (BBCA Onlus, Rome, Italy), A. Pasquali (ENEA UTTMAT, Rome, Italy), P.F. Roversi (CRA, Florence, Italy). A special thanks is due to S.L. Clement (USDA-ARS WRPIS Pullman, WA, USA), B.G. Rector (USDA-ARS, PWA, Reno NV, USA) and L. Smith (USDA-ARS, EBCL, Montpellier, France) and G. Tonne (Rome, Italy) for their suggestions and reviews of the manuscript. This work was carried out with the financial support of the IAEA Technical Contract No: 15804 ('Laboratory and Confined-Field Assessment for the Feasibility of an Integrated SIT Project for the Control of the Red Palm Weevil in Italy') and of the Mipaaf PROPALMA Project. It is also part of Sapienza University of Rome's within the Project FARI 2010 prot.C26I10SBMC 'Bioinformatica, ecologia molecolare e specie invasive: in silico mining di librerie genomiche da pirosequenziamento 454 per l'individuazione di loci microsatelliti' and the University Project 2012 prot. C26A12KRHP 'Tagged Next Generation Sequencing e in silico mining di polimorfismi nucleotidici (SNP) nello studio delle invasioni biologiche'.

\section{References}

Abdel-Azim, M.M., Vidyasagar, P.S.P.V., Aldosari, S.A. \& Mumtaz, R. (2012) Impact of mating frequency on fecundity, fertility and longevity of red palm weevil, Rhynchophorus ferrugineus (Olivier) (Coleoptera: Curculionidae). Journal of Agricultural Science and Technology A 2, 520-528.

Al-Ayedh, H.Y. \& Rasool, K.G. (2010) Sex ratio and the role of mild relative humidity in mating behaviour of red date palm weevil Rhynchophorus ferrugineus Oliv. (Coleoptera: Curculionidae) gamma-irradiated adults. Journal of Applied Entomology 134, 157-162.

Arnone, S., Musmeci, S., Catarci, S., Sasso, R., Nobili, P. \& Cristofaro, M. (2014) Allevamento del punteruolo rosso delle palme: un contributo per la sperimentazione in campo e per studi di laboratorio. p. 107 in XXIV Italian Congress of Entomology, 9-14 June 2014, Orosei (NU), Società Entomologica Italiana.

Baccaro, S., Cecilia, A. \& Pasquali, A. (2005) Irradiation Facility at ENEA-CASACCIA Centre (Rome) ENEA: ENEA Report RT/ 2005/28/FIS 29 pp.

Barclay, H.J. (2005) Mathematical models for the use of sterile insects. pp. 147-174 in Dick, V.A., Hendrichs, J. \& Robinson, A.S. (Eds) Sterile Insect Technique Principles and Practice in Area-Wide Integrated Pest Management. The Netherlands, Springer.

Belvedere, S., La Marca, A., Marcari, V., Senia, G. \& De Biase, A. (2014) In silico mining of microsatellite markers for the Red Palm Weevil as contribution to its invasion management. Conservation Genetics Resources 6, 947-948.

Benjamini, Y. \& Hochberg, Y. (1995) Controlling the false discovery rate: a practical and powerful approach to multiple testing. Journal of the Royal Statistical Society B57, 289-300.

Boorman, E. \& Parker, G.A. (1976) Sperm (ejaculate) competition in Drosophila melanogaster, and the reproductive value of females to males in relation to female age and mating status. Ecological Entomology 1, 145-155.

Conner, J.K. (1995) Extreme variability in sperm precedence in the fungus beetle, Bolitotherus cornutus (Coleoptera Tenebrionidae). Ethology Ecology \& Evolution 7, 277-280.

Cook, P.A., Harvey, I.F. \& Parker, G.A. (1997) Predicting variation in sperm precedence. Philosophical Transactions of the Royal Society $B, 352,771-780$.

Cristofaro, M., Sasso, R., Musmeci, S., Arnone, S., Di Ilio, V., De Biase, A. \& Belvedere, S. (2011) Primi risultati relativi ad uno studio di fattibilità della tecnica dell'insetto sterile per il controllo di. Rhynchophorus ferrugineus Olivier. p. 292 in XXIII Italian Congress of Entomology, 13-16 June 2011, Genova, Società Entomologica Italiana.

Danielsson, I. (1998) Mechanisms of sperm competition in insects. Annales Zoologici Fennici 35, 241-257.

Dembilio, Ó. \& Jacas, J.A. (2011) Basic bio-ecological parameters of the invasive Red Palm Weevil, Rhynchophorus ferrugineus (Coleoptera: Curculionidae), in Phoenix canariensis under Mediterranean climate. Bulletin of Entomological Research 101, 153-163.

El-Mergawy, R.A.A.M. \& Al-Ajlan, A.M. (2011) Red palm weevil, Rhynchophorus ferrugineus (Olivier): economic importance, biology, biogeography and integrated pest management. Journal of Agricultural Science and Technology A 1, 1-23.

EPPO Standards (2015) A1 and A2 lists of pests recommended for regulation as quarantine pests. European and Mediterranean Plant Protection Organization. 21 Boulevard Richard Lenoir, 75011 Paris, France, September 2015. https://www.eppo. int/QUARANTINE/listA2.htm.

Esteban-Duràn, J., Yela, J.L., Crespo, F.B. \& Alvarez, A.J. (1998) Biology of red palm weevil, Rhynchophorus ferrugineus (Olivier) (Coleoptera: Curculionidae: Rhynchophorinae), in the laboratory and field life cycle, biological characteristics in its zone of introduction in Spain, biological method of detection and possible control. Boletin de Sanidad Vegetal Plagas 24, 737-748.

Faghih, A.A. (1996) The biology of red palm weevil, Rhynchophorus ferrugineus Oliv. (Coleoptera, Curculionidae) in Saravan region (Sistan \& Balouchistan province, Iran). Applied Entomology and Phytopathology 63, 16-18.

Faleiro, J.R. (2006) A review of the issues and management of the red palm weevil Rhynchophorus ferrugineus (Coleoptera: Rhynchophoridae) in coconut and date palm during the last one hundred years. International Journal of Tropical Insect Science 26, 135-154.

FAO (2005) Provisional Additions, Glossary of Phytosanitary Terms. Rome, Italty, Secretariat of the International Plant Protection Convention (IPPC), FAO.

Gothi, K.K., Hire, R.S., Vijayalakshmi, N. \& Dongre, T.K. (2007) Studies on mating behaviour of radio-sterilized males of Red Palm Weevil, Rhynchophorus ferrugineus Olivier. Journal of Nuclear Agriculture and Biology 36, 65-72.

Gwynne, D.T. (1984) Male mating effort, confidence of paternity, and insect sperm competition. pp. 117-149 in Smith, R.L. (Ed.) Sperm Competition and the Evolution of Animal Mating Systems. New York, Academic Press Inc.

Harano, T., Nakamoto, Y. \& Miyatake, T. (2008) Sperm precedence in Callosobruchus chinensis estimated using the sterile male technique. Journal of Ethology 26, 201-206.

Harari, A.R., Landolt, P.J., O'Brien, C.W. \& Brockmann, H.J. (2003) Prolonged mate guarding and sperm competition in the weevil Diaprepes abbreviatus (L.). Behavioral Ecology 14, 89-96.

Hendrichs, J.H., Robinson, A.S., Cayol, J.P. \& Enkerlin, W. (2002) Medfly Area-Wide Sterile Insect Technique programmes for prevention, suppression or eradication: the importance of mating behavior studies. Florida Entomologist 85, 1-13.

Ince, S., Porcelli, F. \& Al-Jboory, I. (2011) Egg laying and egg laying behavior of red palm weevil Rhynchophorus ferrugineus (Olivier) 1790 (Coleoptera: Curculionidae). Agriculture and Biology Journal of North America 2, 1368-1374.

Inghilesi, A., Mazza, G., Cini, A. \& Cervo, R. (2014) Comportamento sociale e riproduttivo del punteruolo rosso delle palme: approfondire le conoscenze per contrastare questo flagello. Atti Accademia Nazionale Italiana di Entomologia 61, 189-192. 
Inghilesi, A., Mazza, G., Cervo, R. \& Cini, A. (2015) A network of sex and competition: the promiscuous mating system of an invasive weevil. Current Zoology 61, 85-97.

Ju, R.T., Wang, F., Wan, F.H. \& Li, B. (2011) Effect of host plants on development and reproduction of Rhynchophorus ferrugineus (Olivier) (Coleoptera: Curculionidae). Journal of Pest Science 84, 33-39.

Kaakeh, W. (2005) Longevity, fecundity, and fertility of the red palm weevil, Rynchophorus ferrugineus Olivier (Coleoptera: Curculionidae) on natural and artificial diets. Emirates Journal of Agricultural Sciences 17, 23-33.

Kehat, M. (1999) Threat to date palms in Israel, Jordan and Palestian authority by the Red Palm Weevil, Rhynchophorus ferrugineus. Phytoparasitica 27, 241-242.

Klassen, W. (2005) Area-wide integrated pest management and the Sterile Insect Technique. pp. 39-68 in Dyck, V.A., Hendrichs, J. \& Robinson, A.S. (Eds) Sterile Insect Technique: Principles and Practice in Area-Wide Integrated Pest Management. The Netherlands, Springer.

Knipling, E.F. (1955) Possibilities of insect control or eradication through the use of sexually sterile males. Journal of Economic Entomology 48, 459-462.

Knipling, E.F. (1968) The potential role of sterility for pest control. pp. 7-40 in LaBrecque, G.C. \& Smith, C.N. (Eds) Principles of Insect Chemosterilization. New York, USA, Appleton-Century-Crofts.

Krishnakumar, R. \& Maheshwari, P. (2007) Assessment of the Sterile Insect Technique to manage Red Palm Weevil Rhynchophorus ferrugineus in coconut. pp. 475-485 in Vreysen, M.J.B., Robinson, A.S. \& Hendrichs, J. (Eds) Area-Wide Control of Insect Pests. The Netherlands, Springer.

Lance, D.R. \& McInnis, D.O. (2005) Biological Basis of the Sterile Insect Technique. pp. 69-94 in Dyck, V.A., Hendrichs, J. \& Robinson, A.S. (Eds) Sterile Insect Technique: Principles and Practice in Area-Wide Integrated Pest Management. The Netherlands, Springer.

Lee, S.G., McCombs, S.D. \& Saul, S.H. (2003) Sperm precedence of irradiated Mediterranean fruit fly males (Diptera: Tephritidae). Proceedings of Hawaiian Entomological Society 36, 47-59.

Lewis, S.M. \& Austad, S.N. (1990) Sources of intraspecific variation in sperm precedence in red flour beetles. The American Naturalist 135, 351-359.

Llácer, E., Santiago-Álvarez, C. \& Jacas, J.A. (2013) Could sterile males be used to vector a microbiological control agent? The case of Rhynchophorus ferrugineus and Beauveria bassiana. Bulletin of Entomological Research 103, 241-250.

Mazza, G., Francardi, V., Inghilesi, A.F., Stasolla, G., Benvenuti, C., Cini, A., Barzanti, G.P., Cito, A., Arnone, S., Cristofaro, M., Musmeci, S., Sasso, R., Camerota, M., Cervo, R. \& Roversi, P.F. (2014) Analisi del comportamento sociale e riproduttivo dei maschi sterili di Rhynchophorus ferrugineus: implicazioni per il controllo biologico con agenti entomopatogeni. p. 103 in XXIV Italian Congress of Entomology, 9-14 June 2014 Orosei (NU), Società Entomologica Italiana.

Mazza, G., Inghilesi, A.F., Stasolla, G., Cini, A., Cervo, R., Benvenuti, C., Francardi, V., Cristofaro, M., Arnone, S. \& Roversi, P.F. (2016) Sterile Rhynchophorus ferrugineus males efficiently impair reproduction while maintaining their sexual competitiveness in a social context. Journal of Pest Science 89, 459-468.

Murphy, S.T. \& Briscoe, B.R. (1999) The red palm weevil as an alien invasive: biology and the prospects for biological control as a component of IPM. Biocontrol News and Information 20, 35-46.

Musmeci, S., Cristofaro, M., Arnone, S., Sasso, R., Baccaro, S., Pasquali, A. \& Catarci, S. (2013) Controllo del punteruolo rosso mediante la tecnica del maschio sterile (SIT): utopia o realtà? Atti Accademia Nazionale Italiana di Entomologia 61, 239-246.

Paoli, F., Dallai, R., Cristofaro, M., Arnone, S., Francardi, V. \& Roversi, P.F. (2014) Morphology of the male reproductive system, sperm ultrastructure and $\gamma$-irradiation of the red palm weevil Rhynchophorus ferrugineus Oliv. (Coleoptera: Dryophthoridae). Tissue and Cell 46, 274-285.

Prabhu, S.T. \& Patil, R.S. (2010) Studies on the biological aspects of red palm weevil, Rhynchophorus ferrugineus (Oliv.). Karnataka Journal of Agricultural Sciences 22, 732-733.

Prabhu, S.T., Dongre, T.K. \& Patil, R.S. (2010) Effect of irradiation on the biological activities of red palm weevil, Rhynchophorus ferrugineus Olivier. Karnataka Journal of Agricultural Sciences 23, 186-188.

Rahalkar, G.W., Harwalkar, M.R., Rananavare, H.D., Shantaram, K. \& Ayengar, A.R.G. (1973) Laboratory studies on radiation sterilization of Rhynchophorus ferrugineus males. Journal of Plantation Crops 1, 141-145.

Rahalkar, G.W., Harwalkar, M.R. \& Rananavare, H.D. (1975) Laboratory studies on sterilization of male Rhynchophorus ferrugineus. pp. 261-267 in Sterility Principle for Insect Control 1974. Vienna, Austria, International Atomic Energy Agency (Ed.).

Rahalkar, G.W., Harwalkar, M.R., Rananvare, H.D., Kurian, C., Abrham, V.A. \& Koya, K.M.A. (1977) Preliminary field studies on the control of the red palm weevil, Rhynchophorus ferrugineus using radio sterilized males. Journal of Nuclear Agriculture and Biology 6, 65-68.

Ramachandran, C.P. (1991) Effect of gamma radiation on various stages of red date palm weevil, Rhynchophorus ferrugineus Oliv. Journal of Nuclear Agriculture and Biology 3, 218-221.

Robinson, A.S. \& Hendrichs, J. (2005) Prospects for the future development and application of the sterile insect technique. pp. 727-760 in Dyck, V.A., Hendrichs, J. \& Robinson, A.S. (Eds) Sterile Insect Technique: Principles and Practice in Area-Wide Integrated Pest Management. The Netherlands, Springer.

Rugman-Jones, P.F., Hoddle, C.D., Hoddle, M.S. \& Stouthamer, R. (2013) The lesser of two weevils: molecular-genetics of pest palm weevil populations confirm Rhynchophorus vulneratus (Panzer 1798) as a valid species distinct from $R$. ferrugineus (Olivier 1790), and reveal the global extent of both. PLoS ONE 8, e78379.

Scolari, F., Yuval, B., Gomulski, L.M., Schetelig, M. F., Gabrieli, P., Bassetti, F., Wimmer, E.A., Malacrida, A.R. \& Gasperi, G. (2014) Polyandry in the medfly - shifts in paternity mediated by sperm stratification and mixing. BMC Genetics 15(Suppl. 2), S10, 1-8. doi: 10.1186/1471-2156-15-S2-S10.

Sillen-Tullberg, B. (1981) Prolonged copulation: a male 'postcopulatory' strategy in a promiscuous species, Lygaeus equestris (Heteroptera: Lygaeidae). Behavioral Ecology and Sociobiology 9, 283-289.

Simmons, L.W. (2001) Sperm Competition and its Evolutionary Consequences in the Insects. Princeton, New Jersey, USA, Princeton University Press (Ed.).

SPSS Inc. Released (2008) SPSS Statistics for Windows, Version 17.0. Chicago: SPSS Inc.

Squires, Z.E., Wong, B., Norman, M.D. \& Stuart-Fox, D. (2015) Last male sperm precedence in a polygamous squid. Biological Journal of the Linnean Society 116(2), 277-287.

Whitten, M. \& Mahon, R. (2005) Misconception and constraints. pp. 601-626 in Dyck, V.A., Hendrichs, J. \& Robinson, A.S (Eds) Sterile Insect Technique: Principles and Practice in Area-Wide Integrated Pest Management. The Netherlands, Springer. 